\title{
Functional Removable Prosthetic Rehabilitation Using the Electronic Condylograph: A Case Report
}

\author{
Eleonora Mangone*(D), Enrico Cataneo*(D), Leonzio Fortunato $(D)$ and Luisa Cresti \\ Department of Health Sciences, School of Dentistry, Magna Graecia University of Catanzaro, Viale Europa, \\ 88100 Catanzaro, Italy; leo@unicz.it (L.F.); crestident@gmail.com (L.C.) \\ * Correspondence: eleonora.mangone93@gmail.com (E.M.); ecataneo@inwind.it (E.C.); \\ Tel.: +39-393-927-8167 (E.C.)
}

check for updates

Citation: Mangone, E.; Cataneo, E.; Fortunato, L.; Cresti, L. Functional Removable Prosthetic Rehabilitation Using the Electronic Condylograph: A Case Report. Prosthesis 2021, 3, 437-445. https://doi.org/10.3390/ prosthesis3040039

Academic Editor: Bruno Chrcanovic

Received: 6 November 2021

Accepted: 15 December 2021

Published: 20 December 2021

Publisher's Note: MDPI stays neutral with regard to jurisdictional claims in published maps and institutional affiliations.

Copyright: (c) 2021 by the authors. Licensee MDPI, Basel, Switzerland. This article is an open access article distributed under the terms and conditions of the Creative Commons Attribution (CC BY) license (https:/ / creativecommons.org/licenses/by/ $4.0 /)$.

\begin{abstract}
This article describes the design of complete removable prostheses following the Slavicek philosophy, which involves the integration between condylographic data and an individual cephalometric study of the patient. The electronic condylograph is a device that records the mandibular movements made by the patient. This case report shows how condylography data are useful not only in the individual articulator setting, but also for diagnostic completion and for planning a functional prosthetic rehabilitation.
\end{abstract}

Keywords: electronic codylograph; removable prosthesis; edentulism; temporomandibular joints; dental occlusion; elderly patient; digital prosthetic planning; treatment strategies

\section{Introduction}

Tooth loss seriously affects the quality of the patients' lives, not only in terms of the repercussions on a physical and functional level, but also for the social and psychological discomfort that follows. To date, a removable prosthesis represents one of the most suitable treatment options, especially for totally edentulous subjects [1,2]. The masticatory function plays an important role in the patient's general health. Several studies have shown that inefficiency in chewing is associated with cardiovascular disease, increased risk of cognitive impairment, and changes in eating habits, which, if not controlled, can lead to malnutrition [3-7]. Therefore, when designing a prosthesis, the dentist must pay more attention to the functional aspect than to the aesthetics of the prosthetic device. The clinical use of the electronic condylograph can be of great support for a functional analysis $[8,9]$. This device allows one to record the mandibular movements made by the patient in the three spatial planes ( $x, y, z$ coordinates), starting from a centric relation position $[10,11]$. The recorded condylar paths are transferred to the personal computer and processed by a specific software $[10,11]$. According to Slavicek, the integration of these data with the patient's cephalometric parameters allows one to design customized, functionally correct and aesthetically harmonious prostheses [9].

The aim of this article is to show how the electronic condylograph may provide the parameters for articulator setting, as well as information about the neuromuscular system, the morphofunctional state of the temporomandibular joints (TMJs), and the reciprocal connection between the mandibular dynamics and dental occlusion [9-12]. To this end, the JMAnalyser + (Zebris Medical GmbH, Isny im Allgäu, Germany), an ultrasonic motioncapture device supported by the software program "WINJAW+" (Zebris Medical GmbH, Isny im Allgäu, Germany), was used.

\section{Case Report}

A 78-year-old female patient presented to the dental office because she was dissatisfied with the aesthetics of her complete removable prostheses (Figure 1); furthermore, she complained of postural pains, neck cramps, headaches, and digestive disorders. 


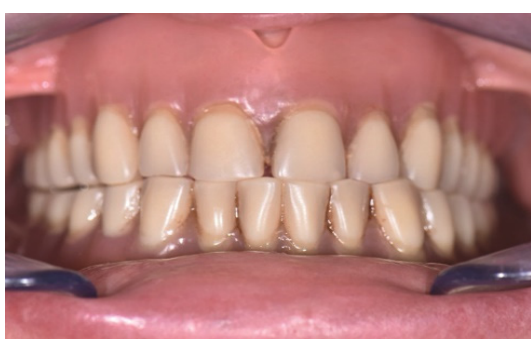

(a)

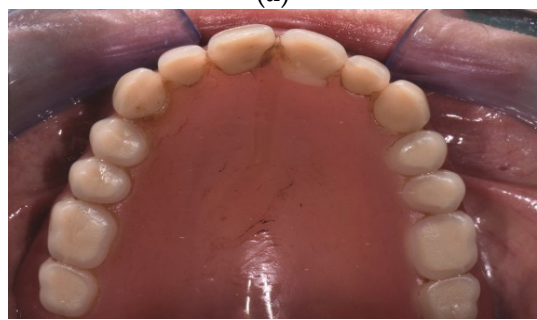

(c)

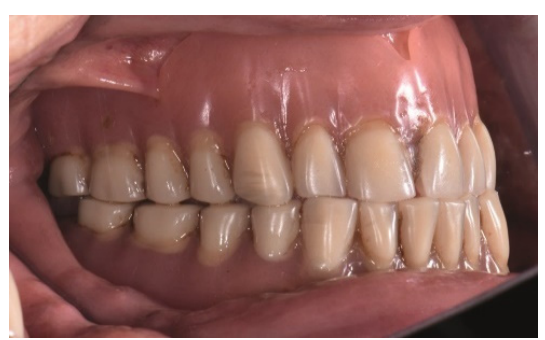

(b)

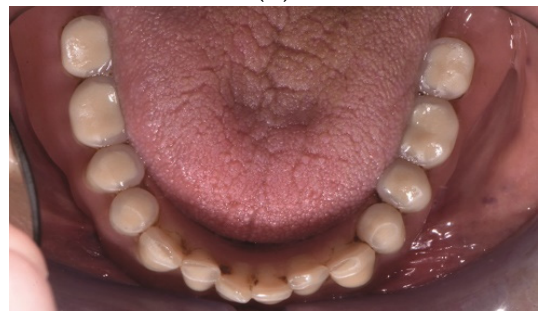

(d)

Figure 1. Intraoral view of old complete removable prostheses: (a) frontal view; (b) right lateral view; (c) occlusal view of upper jaw; (d) occlusal view of lower jaw.

After the anamnestic data collection, a physical examination (intra-oral and extra-oral) was performed and it revealed a generalized muscle and joint pain upon palpation. Keeping the old complete removable prostheses in the oral cavity, occlusal contacts were analyzed, intra- and extra-oral photographs were taken, and routine radiographic examinations were carried out: orthopantomography (OPT) (Figure 2a), antero-posterior teleradiography (AP Ceph) (Figure 2b), and latero-lateral teleradiography (Lat Ceph) (Figure 2c).

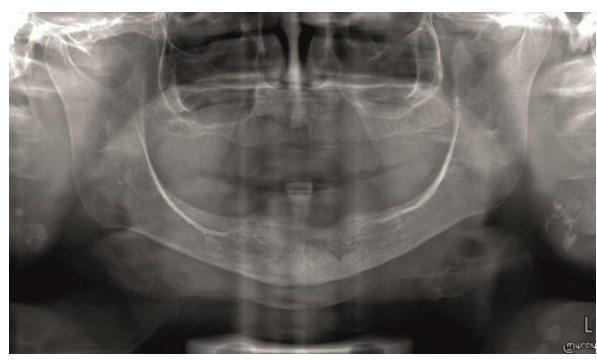

(a)

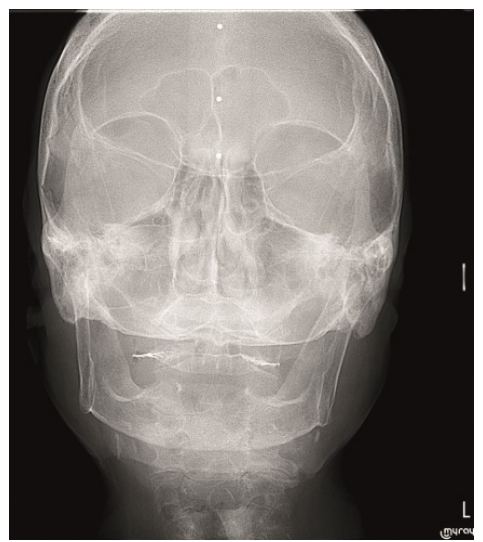

(b)

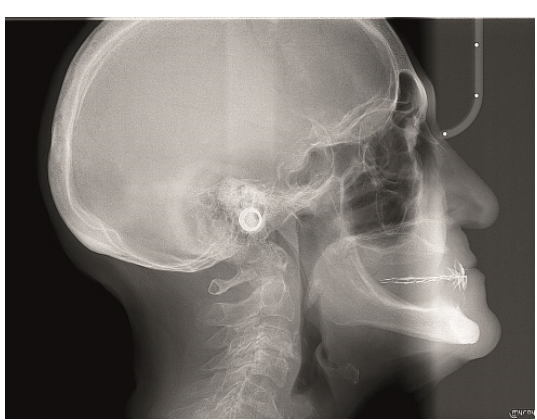

(c)

Figure 2. Initial radiographic images: (a) initial orthopantomography (OPT); (b) initial anteroposterior teleradiography (AP Ceph); (c) initial latero-lateral teleradiography (Lat Ceph). 
The collected information showed that the old complete removable prostheses were incongruous. The proposed treatment plan involved the realization of new complete removable prostheses with bilateral balanced occlusion. In agreement with the patient, the complete removable prostheses were designed following the Slavicek philosophy, which refers to the integration between condylography data and an individual cephalometric study of the patient.

The condylographic tracings were recorded on the patient with the JMAnalyser + (Zebris Medical GmbH, Isny im Allgäu, Germany) and processed by the software program "WINJAW+" (Zebris Medical GmbH, Isny im Allgäu, Germany). Subsequently, they were evaluated through the interpretation of specific parameters: quantity, quality, characteristic, start/endpoint and coincidence. The analysis of these tracings revealed muscular problems and joint instability, associated with a mandibular latero-deviation, which was already evident in the AP Ceph and also highlighted by the great discrepancy between the values of the Sagittal Condylar Inclination (SCI or eminence angle): 47.3 degrees on the right side and 32.7 degrees on the left. The values of the Transversal Condylar Inclination (TCI or Bennett angle) were also different between the two condyles: 6.1 degrees on the right; 0 degrees on the left (Figure 3).

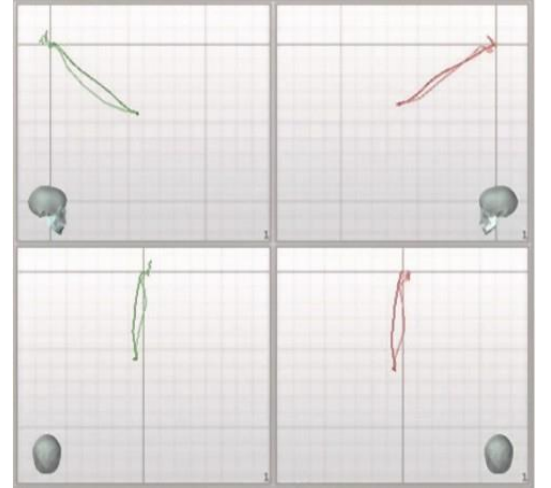

(a)

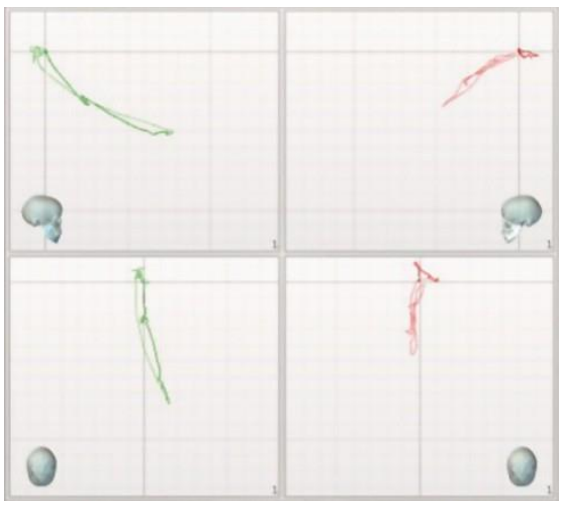

(c)

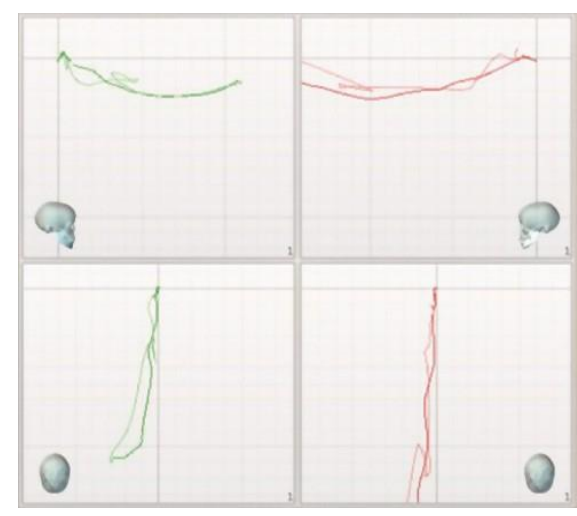

(b)

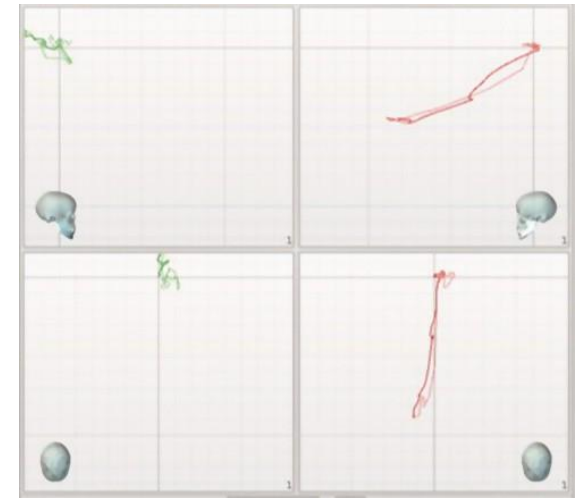

(d)

\begin{tabular}{|c|c|c|c|}
\hline \multirow{2}{*}{ Sagittal Condyle Incl. (FH) } & $\mathrm{L}$ & 32,7 & 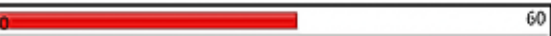 \\
\hline & $R$ & 47,3 & 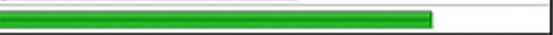 \\
\hline \multirow{2}{*}{ Bennett Angle } & $L$ & 0,0 & 60 \\
\hline & $\mathrm{R}$ & 6,1 & 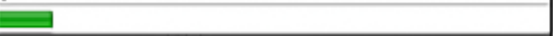 \\
\hline
\end{tabular}

(e)

Figure 3. Initial condylographic recordings: (a) protrusion/retrusion tracing; (b) open/close of the mouth tracing; (c) mediotrusion right tracing; (d) mediotrusion left tracing; (e) SCI and TCI values of the right (green) and left (red) condyles.

The cephalometric tracing, performed with Lat Ceph, highlighted a severe skeletal class II (brachyfacial type), an inadequate occlusal plane (OP), both for position and 
inclination (OPI: 18.8 degrees, referring to the axis-orbital plane (AOP)), and an occlusal vertical dimension (OVD), which is much smaller (38.5 degrees) than the Individual Norm (41.3 degrees) (Figure 4a). On the basis of standardized tables included in the Slavicek protocol, how much the incisal pin of the articulator should be elevated to increase the OVD in order to be similar to the Individual Norm was calculated. The alginate impressions of the patient's edentulous arches were made with a perforated rigid (metal) stock tray and plaster casts were developed. Subsequently, the plaster casts with the old complete removable prostheses were mounted in a centric relation position on the articulator, applying a $10 \mathrm{~mm}$ increase in the incisal pin so that the correct re-establishment of the intermaxillary relation was achieved (Figure $4 b$ ).

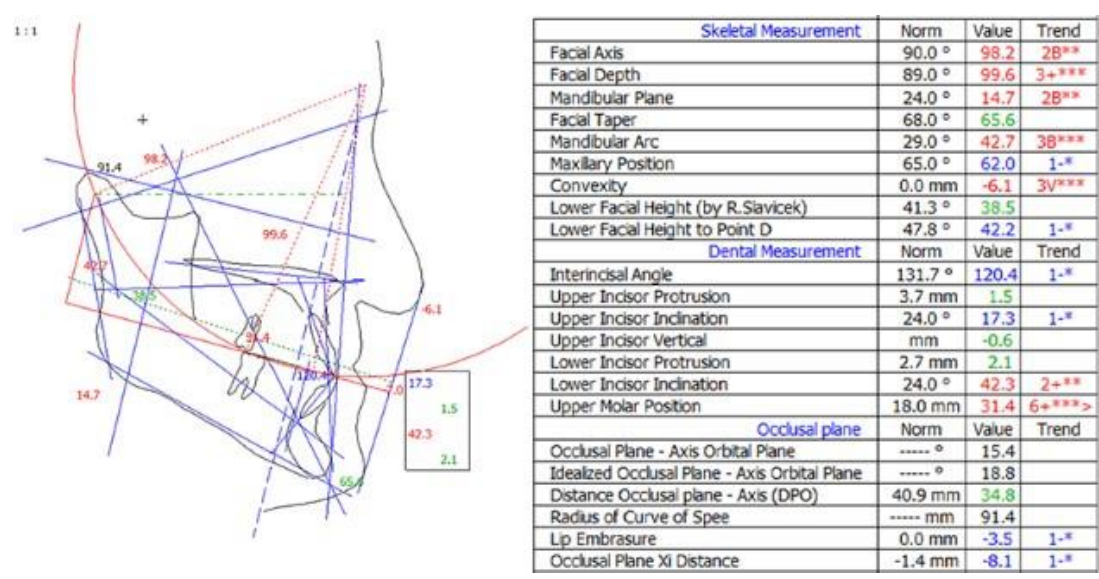

(a)

\begin{tabular}{|l|r|r|r|r|r|r|r|r|r|r|r|r|r|}
\hline Incisal Pin Height & 0.0 & 1.0 & 2.0 & 3.0 & 4.0 & 5.0 & 6.0 & 8.0 & 10.0 & 12.0 & 14.0 & 16.0 & 20.0 \\
\hline Lower Facial Height & 38.5 & 38.9 & 39.4 & 39.8 & 40.2 & 40.6 & 41.0 & 41.8 & 42.6 & 43.4 & 44.1 & 44.8 & 46.2 \\
\hline LFH. (Norm) & 41.3 & 41.4 & 41.5 & 41.6 & 41.7 & 41.8 & 42.0 & 42.2 & 42.4 & 42.6 & 42.8 & 43.0 & 43.4 \\
\hline LFH. (Variation) & -0.0 & 0.4 & 0.9 & 1.3 & 1.7 & 2.1 & 2.5 & 3.3 & 4.1 & 4.9 & 5.6 & 6.3 & 7.7 \\
\hline Menton Vertical & 0.0 & 0.6 & 1.2 & 1.8 & 2.4 & 2.9 & 3.5 & 4.6 & 5.6 & 6.6 & 7.6 & 8.5 & 10.2 \\
\hline Pogonion Sagittal & 0.0 & -0.7 & -1.4 & -2.2 & -2.9 & -3.6 & -4.4 & -5.9 & -7.4 & -9.0 & -10.5 & -12.1 & -15.2 \\
\hline Incision Inf. Vertical & 0.0 & 0.6 & 1.2 & 1.8 & 2.4 & 3.0 & 3.6 & 4.7 & 5.7 & 6.8 & 7.8 & 8.8 & 10.7 \\
\hline Incision Inf. Sagittal & 0.0 & -0.5 & -1.1 & -1.6 & -2.2 & -2.7 & -3.3 & -4.5 & -5.6 & -6.8 & -8.0 & -9.3 & -11.8 \\
\hline
\end{tabular}

(b)

Figure 4. Initial individual cephalometric study: (a) digital cephalometric tracing according to Slaviceck: shows the value of the vertical dimension, the inclination of the occlusal plane and the skeletal class; (b) incisal pin table: blue box shows the OVD and Individual Norm values calculated from the cephalometric tracing, with the incisal pin of the articulator at $0 \mathrm{~mm}$; red box shows the OVD and Individual Norm values in the Therapeutical Position (ThP), obtained with a $10 \mathrm{~mm}$ elevation of the incisal pin.

This increase was divided into two steps of $5 \mathrm{~mm}$ each. In the first step, the gap was filled by building two resin splints on the old complete removable prostheses: an upper one, on which the cusps of the upper active centric line of old complete removable prostheses were simulated, and a smooth lower one. Eight weeks later, after obtaining a stable occlusion, the incisal pin was increased by $5 \mathrm{~mm}$ more and the gap was filled by adding resin to the lower splint. The gradual increase in the OVD determined mastictory muscles deconditioning and, as a consequence, the new position of the jaw, the Therapeutic Position (ThP), was defined (Figure 5). 


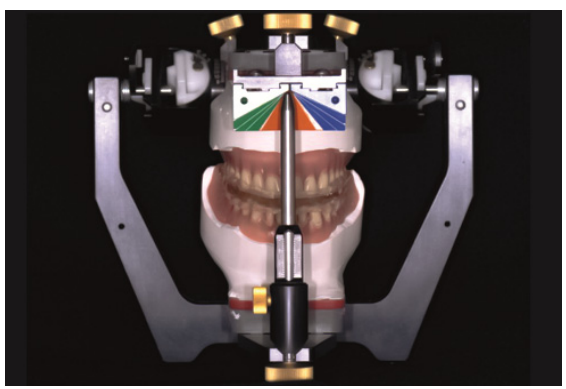

Figure 5. Models mounted on articulator in ThP after splint therapy: frontal view.

After three months, during the follow-up the patient did not report any muscle and joint discomfort on palpation, episodes of postural pain, neck cramps, headaches or digestive disorders. Therefore, the radiographic examinations and a condylographic and cephalometric analysis were performed again, keeping the old complete removable prostheses and the splints in the oral cavity. The teleradiographs and the cephalometric tracing showed an improvement in the mandibular latero-deviation and the achievement of a vertical compensation: by increasing the OVD (41.9 degrees), the patient was reclassified to skeletal class I (Figure 6).

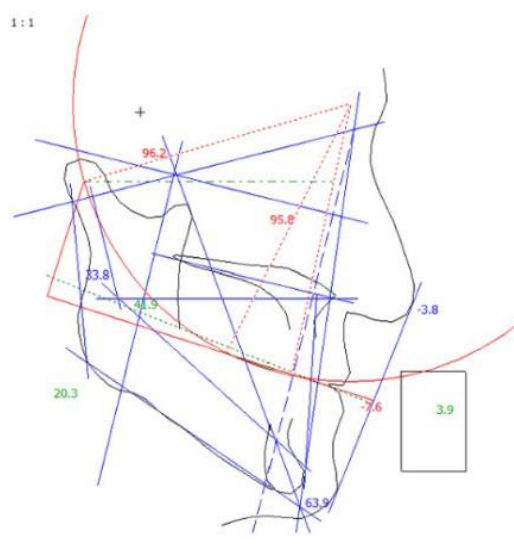

\begin{tabular}{|c|c|c|c|}
\hline Skeletal Measurement & Norm & Value & Trend \\
\hline Facial Axis & $90.0^{\circ}$ & 96.2 & $2 \mathrm{~B}^{*=}$ \\
\hline Fadial Depth & $89.0^{\circ}$ & 95.8 & $2+x=$ \\
\hline Mandibular Plane & $24.0^{\circ}$ & 20.3 & \\
\hline Facial Taper & $68.0^{\circ}$ & 63.9 & $1 \mathrm{D}^{*}$ \\
\hline Mandibular Arc & $29.0^{\circ}$ & 33.8 & $1 \mathrm{~B}^{*}$ \\
\hline Maxilary Position & $65.0^{\circ}$ & 65.3 & \\
\hline Convexity & $0.0 \mathrm{~mm}$ & -3.8 & $1 \mathrm{~V}^{*}$ \\
\hline Lower Facial Height (by R.Slavicek) & $42.8^{\circ}$ & 41.9 & \\
\hline Lower Facial Height to Point D & $49.3^{\circ}$ & 46.6 & \\
\hline Dental Measurement & Norm & Value & Trend \\
\hline Interincisal Angle & $132.8^{\circ}$ & & \\
\hline Upper Incisor Protrusion & $4.3 \mathrm{~mm}$ & 3.9 & \\
\hline Upper Incisor Inclination & $23.1^{\circ}$ & & \\
\hline Upper Indsor Vertical & $\mathrm{mm}$ & & \\
\hline Lower Indisor Protrusion & $1.2 \mathrm{~mm}$ & & \\
\hline Lower Incisor Inclination & $24.1^{\circ}$ & & \\
\hline Upper Molar Postion & $18.0 \mathrm{~mm}$ & & \\
\hline Ocdusal plane & Norm & Value & Trend \\
\hline Occlusal Plane - Axis Orbital Plane & 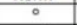 & & \\
\hline Idealzed Occlusal Plane - Axis Orbtal Plane & $\ldots .+0^{\circ}$ & 22.6 & \\
\hline Distance Occusal plane - Axis (DPO) & $40.9 \mathrm{~mm}$ & & \\
\hline Radius of Curve of Spee & $\mathrm{mm}$ & & \\
\hline Lip Embrasure & $0.0 \mathrm{~mm}$ & & \\
\hline Occusal Plane & $-14 \mathrm{~mm}$ & & \\
\hline
\end{tabular}

(a)

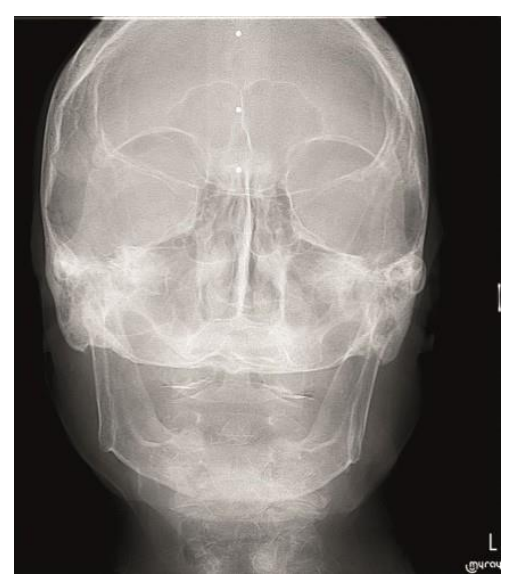

(b)

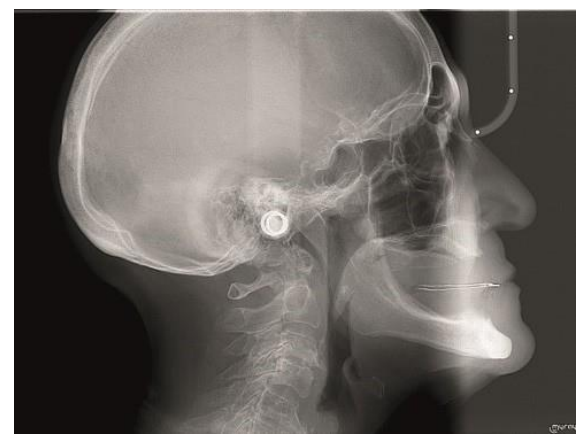

(c)

Figure 6. Individual cephalometric study after splint therapy: (a) digital cephalometric tracing according to Slaviceck after splint therapy: the new OVD value is within the range of Individual Norm; (b) antero-posterior teleradiography (AP Ceph) after splint therapy; (c) latero-lateral teleradiography (Lat Ceph) after splint therapy. 
The condylographic tracings showed an improvement in muscular problems, joint instability, and mandibular latero-deviation, as shown by the SCI values ( 49.5 degrees right; 44.4 degrees left) and the TCI values (4.9 degrees right; 5.3 degrees left), whose similarity is more evident between the two condyles (Figure 7).

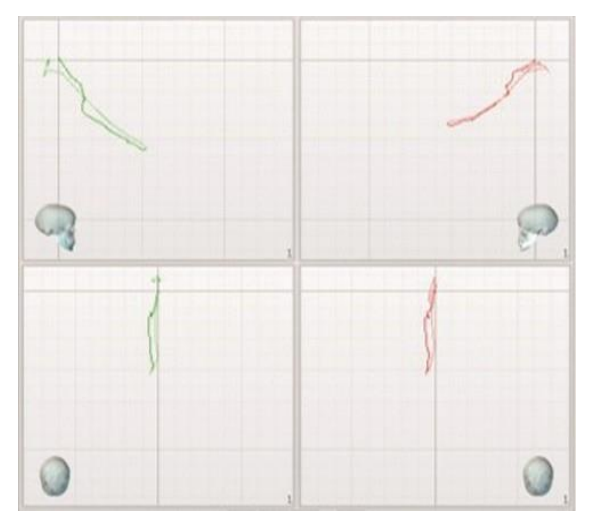

(a)

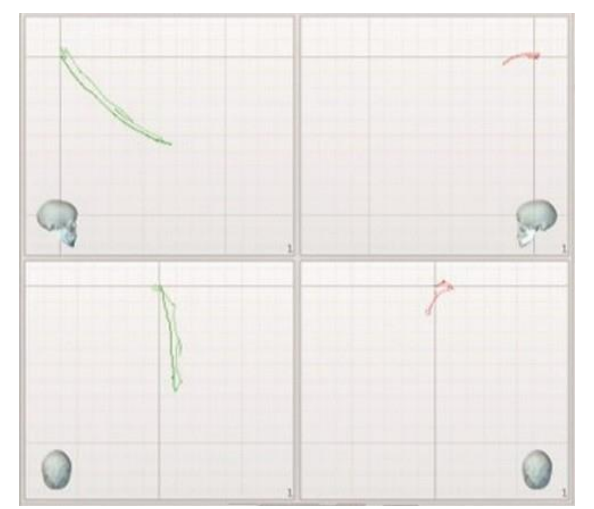

(c)

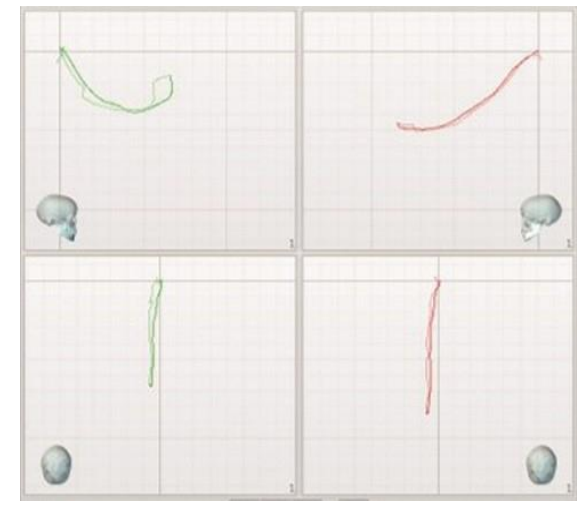

(b)

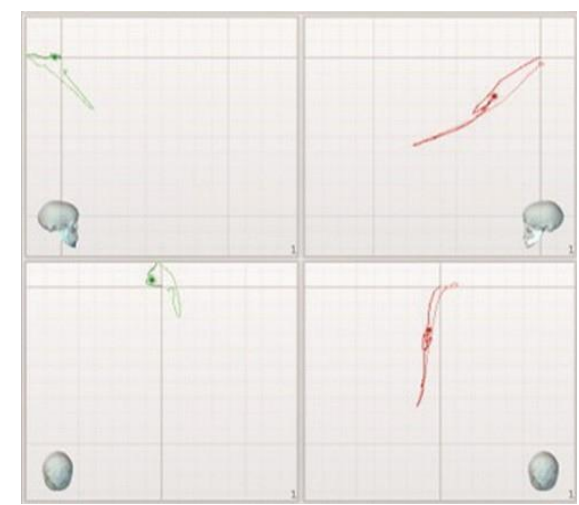

(d)

\begin{tabular}{|lrr|r|}
\hline Sagittal Condyle Incl. (FH) & $\mathrm{L}$ & 44,4 & 0 \\
\hline Bennett Angle & $\mathrm{R}$ & 49,5 & $\overline{0}$ \\
\hline
\end{tabular}

(e)

Figure 7. Condylographic recordings after splint therapy: (a) protrusion/retrusion tracing; (b) open/close of the mouth tracing; (c) mediotrusion right tracing; (d) mediotrusion left tracing; (e) SCI and TCI values of the right (green) and left (red) condyles after splint therapy.

After having verified the accuracy of the treatment plan, all the parameters necessary for the creation of the wax-up were provided to the dental technician:

- The OVD (41.9 degrees), the length of the lower incisors, the ideal OPI (16.6 degrees), and the radius of the curve of Spee $(70 \mathrm{~mm}$ ) were extrapolated (Figure 6) from the cephalometric tracing;

- The SCI (49.5 degrees on the right; 44.4 degrees on the left) and the TCI (4.9 degrees on the right; 5.3 degrees on the left), which are useful for the individual setting of the articulator, and the inclination of the occlusal surfaces of the maxillary teeth (Figure 7) were obtained from the condylographic tracings.

Being an elderly patient, the smile line was evaluated in order to better manage the perioral soft tissues; thus, the length of the lower incisors was defined on the basis of that of the upper ones. To calculate the ideal OPI (16.6 degrees), it was sufficient to subtract 6 degrees from the value obtained from the cephalometric analysis (22.6 degrees), as the 
treatment was set referring to the $\mathrm{FH}$, which differs from the AOP of 6 degrees. The radius of the curve of Spee $(70 \mathrm{~mm})$ was calculated by using the equation:

$$
(-1.42 \times \mathrm{DPO})+134.46
$$

where DPO is the distance between the hinge axis $(\mathrm{AX})$ and the OP.

The inclination of the occlusal surfaces of the maxillary teeth was defined by studying the path drawn by the mandibular teeth on the upper ones during lateral and protrusion movements. As this is a bilateral balanced occlusion, the F1-F2 path, described during the lateral movements, has an inclination equal to the value of the SCI from the first molar to the canine. The F1-F3 and F3-F2 paths, describing the upper incisors during the protrusion movement, have a different inclination: the first is equal to -10 degrees SCI, whereas the second is equal to +10 degrees SCI.

Subsequently, with the wax-up positioned in the oral cavity of the patient, laterolateral teleradiography, cephalometric tracing, condylographic tracings and postural tests were carried out again in order to verify the validity of all data provided to the dental technician. After having verified its accuracy, the wax-up was scanned: the flange of the final complete removable prostheses was made in acrylic resin, while the dental elements were milled in composite with the CAD/CAM system. Finally, the products were finished and delivered to the patient, who was fully satisfied.

During the follow-ups at 3,6 and 12 months, the patient always reported a positive opinion about the aesthetics, function and stability of her new complete removable prostheses and also confirmed the resolution of the episodes of postural pain, neck cramps, headaches and digestive disorders (Figure 8).

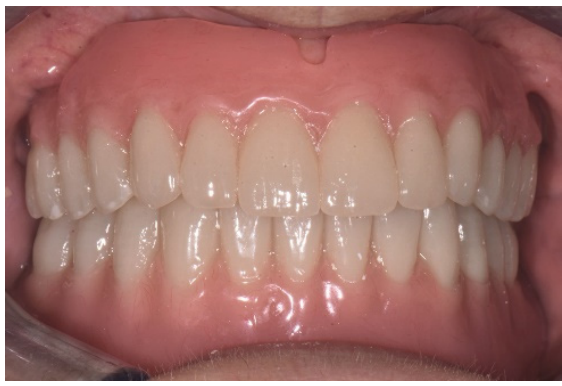

(a)

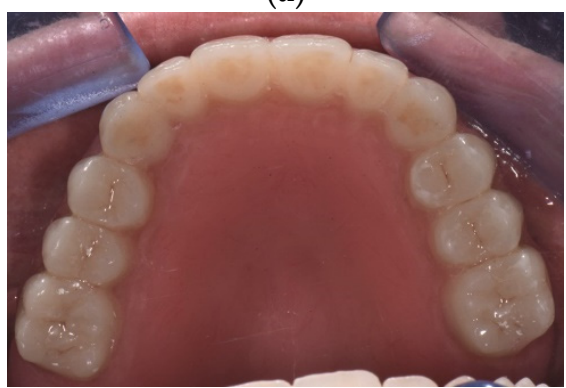

(c)

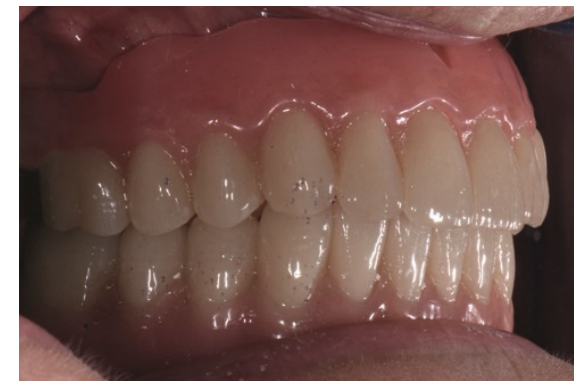

(b)

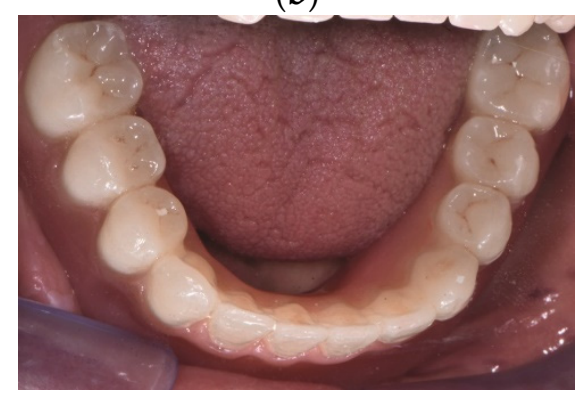

(d)

Figure 8. Intraoral view of definitive complete removable prostheses: (a) Frontal view; (b) right lateral view; (c) occlusal view of upper jaw; (d) occlusal view of lower jaw.

\section{Discussion}

This report shows how the analysis of condylographic tracings and, particularly, the value of the SCI, can guide clinicians in the development of a customized prosthetic design. The SCI, in fact, is closely related to the OPI and the CI [10,13-15]. This is calculated by means of the following equation: 


\section{RCI—DOA (Disocclusal Angle $)=$ CI (Cusp Inclination)}

Normally, the SCI is 45 degrees, the OPI is about $8-10$ degrees (compared to FH), the DOA is $8-10$ degrees and the $\mathrm{CI}$ is $28-30$ degrees. Thanks to these calculations, it was verified that a given OPI allows the desired movement of the cusps during functional movements [10,13-15].

The influence of the SCI on the OPI also affects the value of the radius of the curve of Spee; therefore, as the OPI changes, the DPO and, consequently, the curve of Spee are modified too $[9,13,16]$.

Compared to the mechanical recording systems, the electronic condylograph allows one to study the condylar paths both from a static point of view and from a dynamic one. Another advantage is the possibility of storing, enlarging and overlapping multiple tracings, so as to analyze them more accurately and conduct a re-evaluation over time. Thus, the condylography was performed to collect data that are useful for setting the articulator and for diagnostic purposes, as well as to recognize and correct any TMJ dysfunctions and muscle disorders.

This protocol has limitations related primarily to the long period of the treatment, its management complexity and costs for both the clinician and the patient.

\section{Conclusions}

This clinical report shows how the electronic condylograph can contribute to improving the current standards of daily clinical practice. In fact, a prosthesis that takes into account the individual values of the subject, guarantees excellent aesthetics, greater stability in the oral cavity, and better chewing efficiency; as a result, a greater long-term patient satisfaction is achieved.

Author Contributions: Conceptualization, L.C. and E.M.; resources, L.C.; writing-original draft preparation, E.M.; writing-review and editing, E.M., L.C. and E.C.; supervision, L.F.; project administration, E.C. All authors have read and agreed to the published version of the manuscript.

Funding: This research received no external funding.

Institutional Review Board Statement: Not applicable.

Informed Consent Statement: Informed consent was obtained from all subjects involved in the study.

Data Availability Statement: Not applicable.

Conflicts of Interest: The authors declare no conflict of interest.

\section{References}

1. Xie, Q.; Ding, T.; Yang, G. Rehabilitation of oral function with removable dentures—Still an option? J. Oral Rehabil. 2015, 42, 234-242. [CrossRef] [PubMed]

2. Lee, D.J.; Saponaro, P.C. Management of Edentulous Patients. Dent. Clin. N. Am. 2019, 63, 249-261. [CrossRef] [PubMed]

3. Felton, D.A. Edentulism and comorbid factors. J. Prosthodont. 2009, 18, 88-96. [CrossRef] [PubMed]

4. Felton, D.A. Complete Edentulism and Comorbid Diseases: An Update. J. Prosthodont. 2016, 25, 5-20. [CrossRef] [PubMed]

5. Tanasić, I.; Radaković, T.; Tihaček-Šojić, L.; Milić-Lemić, A.; Soldatović, I. Association between Dentition Status and Malnutrition Risk in Serbian Elders. Int. J. Prosthodont. 2016, 29, 484-486. [CrossRef] [PubMed]

6. Abdulhade Ganem, A.; Sandeepa, N.; Hassan Alkhayri, A.; Mohammed Mousa, Y. Impact of Tooth Loss and Other Risk Factors on Cognitive Impairment in Saudi Female Population. Neurosci. J. 2019, 2, 6086515. [CrossRef] [PubMed]

7. Han, J.; Lee, H.; Han, J.; Suh, S.; Lee, J.; Byun, S.; Kim, K.S.; Kim, S.Y.; Lee, J.-T.; Yoo, E.; et al. Loss of Functional Dentition is Associated with Cognitive Impairment. J. Alzheimer's Dis. 2020, 73, 1313-1320. [CrossRef] [PubMed]

8. Piehslinger, E.; Celar, A.; Celar, R.; Slavicek, R. Computerized axiography: Principles and methods. Cranio 1991, 9, $344-355$. [CrossRef] [PubMed]

9. Slavicek, R. The Masticatory Organ. Functions and Dysfunction, 1st ed.; Gamma, Med.-Wiss. Fortbildungs-AG: Klosterneuburg, Austria, 2002; 542p.

10. Bassetti, N. The Vertical Dimension in Prosthesis and Orthognathodontics: Integration between Function and Aesthetics, 1st ed.; Edra S.p.A.: Milano, Italy, 2019; 224p. 
11. Ahlers, M.O.; Bernhardt, O.; Jakstat, H.; Kordaß, B.; Türp, J.; Schindler, H.; Hugger, A. Motion analysis of the mandible: Guidelines for standardized analysis of computer-assisted recording of condylar movements. Int. J. Comput. Dent. 2015, 18, 201-223. [PubMed]

12. Botos, A.M.; Mesaros, A.; Zimbran, A. The contribution of computerized axiography to the functional evaluation of the temporomandibular joint: A case report. Clujul Med. 2016, 89, 38-442. [CrossRef] [PubMed]

13. Slavicek, G. Okklusionsebene-Occlusal plane. In Kephalometrie—Cephalometry, 1st ed.; dt./engl; Steinbeis-Edition: Stuttgart, Germany, 2011; pp. 199-247.

14. Slavicek, R. Die Funktionellen Determinanten des Kauorgans. Habilitationsschrift; Verlag Zahnärztlich-Medizinisches Schrifttum: München, Germany, 1984.

15. Parlett, K. Anterior Guidance: What Does It Mean to You? Can. J. Restor. Dent. Prosthodont. 2010, 3, 38-44.

16. Orthlieb, J.D.; Slavicek, R. Geometrische interpretation der Spee kurve. (Geometrical interpretation of the curve of Spee.). Z. Stomatol. 1985, 82, 1-18. 